\title{
UMA PROPOSTA DIDÁTICA PARA A MEDIAÇÃO DA LEITURA DE UM LIVRO DE IMAGEM
}

\section{A TEACHING PROPOSAL FOR THE READING MEDIATION OF A PICTURE BOOK}

\author{
Marilia Forgearini NUNES*
}

\begin{abstract}
Resumo: A leitura de imagem é uma experiência importante de ser proporcionada às crianças leitoras nos Anos Iniciais do Ensino Fundamental. O objetivo deste texto é propor um caminho didático para mediar a leitura da imagem a partir do livro de imagem. Essa proposta didática tem como base teórica, também relevante na sua metodologia, a semiótica discursiva (BARROS, 2005; GREIMAS, 2002) e o seu desdobramento voltado ao texto visual, a semiótica plástica (FLOCH, 1985). Para isso, depois de situar alguns conceitos, um exemplo de leitura de um livro de imagem é apresentado, traçando o percurso gerativo de sentido. Esse percurso de sentido também é o caminho para a organização das ações didáticas para a leitura mediada que se descreve. Por fim, algumas reflexões em torno do fazer do mediador, seus modos de ser e agir ou os regimes de interação (LANDOWSKI, 2014) estabelecidos por ele são colocados em pauta. Mediar a leitura do livro de imagem é uma experiência necessária como prática de letramento visual. Isso envolve conhecer como o texto a ser lido produz sentido e assumir um comportamento mediador que reconheça a interação estabelecida como meio de ampliar ou reduzir as possibilidades de sentido no processo didático da mediação.
\end{abstract}

Palavras-chave: Literatura Infantil. Leitura da imagem. Mediação. Letramento visual. Didática.

\begin{abstract}
Considering that image reading is an important experience to be provided to children in elementary school, this paper presents a didactic way to mediate image reading through a picture book. It has as its theoretical support, which is also relevant to its methodology, the discursive semiotics (BARROS, 2005; GREIMAS 2002) and its application to visual text reading - plastic semiotics (FLOCH, 1985). An example of reading an image book is offered, tracing the generative path of meaning, which also serves to organize the didactic actions of the mediated reading. The paper finishes with some reflections on the mediator's role - his or her ways of being and acting - or on the interaction regimes (LANDOWSKI, 2014) established by him or her. It is argued that mediating the process of reading image books is a must do practice of visual literacy, which involves knowing how texts create meaning and recognizing interaction as a way of expanding or reducing the possibilities of meaning in the didactic process.
\end{abstract}

Keywords: Children's literature. Image reading. Mediation. Visual literacy. Didactics.

\section{Introdução}

Este texto fundamenta-se na ideia de que a leitura de imagem é experiência importante na formação sensível da criança, e a sua mediação é necessária na escola para proporcionar práticas de letramento visual. O objetivo é propor um caminho didático para a mediação da

\footnotetext{
* Professora Adjunta da Universidade Federal do Rio Grande do Sul (UFRGS). Doutorado em Educação pela UFRGS. E-mail: mariliaforginunes@gmail.com. ORCID: http://orcid.org/0000-0003-3911-5588.
} 
leitura da imagem. A proposta didática para a leitura de imagem que será descrita tem como texto o livro de imagem, um gênero de livro literário infantil que tem a linguagem visual como elemento de expressão e produção de sentido. Os leitores a serem mediados são as crianças dos Anos Iniciais do Ensino Fundamental. A escolha por esse texto visual-literário justifica-se pela sua presença como publicação presente no mercado editorial brasileiro (mesmo que escassa) e também como livro que pode ser encontrado em acervos de bibliotecas de escolas públicas brasileiras graças ao que se conheceu como Programa Nacional Biblioteca da Escola $\left(\mathrm{PNBE}^{1}\right)$. O público nos Anos Iniciais do Ensino Fundamental é assumido por ser um grupo de leitores para os quais a escola planeja e propõe de modo mais sistemático mediações de leitura do texto verbal e, muitas vezes, deixa pouco espaço para a produção de sentido a respeito da imagem.

Algumas concepções do campo das artes visuais para compreender a imagem como texto produtor de sentido são base para pensar a leitura da imagem. Estudos das artes visuais tornam-se relevantes visto que as reflexões e proposições advindas da alfabetização e da literatura em associação com a educação, normalmente, apoiam suas argumentações no texto verbal, deixando para a imagem um plano de vivências quase inexistentes ou sem mediação consciente. Assim, esses estudos, nos quais a leitura da imagem possui uma discussão mais ampla, principalmente no que diz respeito à compreensão do processo da leitura e de como mediá-la, sustentam o nosso entendimento sobre letramento visual (NUNES, 2013).

Muitos são os autores que abordam a leitura de imagem a partir de diferentes perspectivas. Michael Parsons (1992) e Maria Helena Wagner Rossi (2003) discutem, a partir de uma abordagem psicogenética, as peculiaridades da leitura estética, apontando níveis de compreensão que revelam como o leitor relaciona o que vê na imagem com o mundo que o cerca. Fernando Hernández (2005), com uma abordagem cultural da imagem, coloca o foco da leitura nas relações de poder inerentes às representações imagéticas. María Acaso (2006) assume uma perspectiva de leitura da imagem com base na mesma cultura visual de Hernández (2005) e na semiótica, chamando atenção para a leitura das imagens da contemporaneidade. Ana Claudia de Oliveira (1999), Sandra Ramalho e Oliveira (2009), Moema Rebouças (2000), Neiva Panozzo (2001) e Analice Pillar (1993) são pesquisadoras que tem como perspectiva teórica a semiótica discursiva, enfocando a produção de sentido a

\footnotetext{
${ }^{1}$ O Programa Nacional Biblioteca da Escola (PNBE) promoveu desde 1997 o acesso à cultura e incentivo à leitura, distribuindo acervos de obras de literatura e de referência para alunos e escolas da rede pública. Aconteceu em diferentes formatos e organizações até 2015, tendo sido hoje incorporado pelo Programa Nacional do Livro Didático (PNLD).
} 
partir da relação do leitor com as qualidades sensíveis e inteligíveis da imagem em um determinado contexto.

Assim como Oliveira (1999), Ramalho e Oliveira (2009), Rebouças(2000) e Pillar (1993), assumimos a perspectiva da semiótica discursiva porque suas asserções teóricas são base para nossa compreensão de que a imagem na literatura infantil, isolada ou em associação ao verbal, não é somente representação dos elementos narrativos, mas um texto que tem constituição própria, com linguagem específica e produtor de sentido que se constrói na leitura (PANOZZO, 2001; PANOZZO, 2007; NUNES, 2013; NUNES, 2014). Esse mesmo entendimento é também base para nossa proposição didática da leitura mediada do livro de imagem, como prática que visa o letramento visual dos leitores.

Letrar visualmente é entendido por nós como uma ação vinculada à vivência da leitura, isto é, da interação com textos visuais buscando a construção de sentido a partir da compreensão de como a textualidade se estabelece por meio da linguagem exclusivamente visual.

\begin{abstract}
Depreendemos, portanto, o letramento voltado para o texto visual plástico, da mesma maneira que Paulo Freire (2005, p. 11) compreendeu o processo de alfabetização, como algo que "não se esgota na decodificação pura da palavra escrita ou da linguagem escrita, mas que se antecipa e se alonga na inteligência do mundo". Interessa-nos não apenas a capacidade do leitor identificar os elementos plásticos que compõem a imagem, mas também, principalmente, o modo com que esse leitor, um sujeito produtor de sentido, considera esses elementos na imagem como um todo discursivo. O que queremos é compreender como podemos auxiliar esse leitor a utilizar a sua capacidade de ver de modo que essa ação não se limite à naturalidade descompromissada, mas alcance produção de sentido a partir de um olhar atento, ou seja, como ajudar o leitor a ser letrado visualmente. (NUNES, 2013, p. 79).
\end{abstract}

Além de uma concepção teórica sobre o que é leitura de imagem e do posicionamento conceitual em torno da ideia de letramento, nossa proposição didática para a leitura mediada da imagem em livro de imagem toma por base quatro princípios como essenciais:

1) o livro de imagem não é somente uma narrativa imagética; 2) ler a imagem é compreender o que o texto diz e como diz ou a imagem é constituída de conteúdo e expressão; 3) mediar para a leitura requer uma interação especializada; 4) a prática da leitura mediada é perpassada por diferentes modos de ser e agir que possibilitam a produção de sentido. (NUNES, 2013).

Esses princípios nos auxiliam a organizar o texto a seguir. Primeiro, apresentaremos a leitura de um livro de imagem, tendo os conceitos da semiótica discursiva como base para compreender o que o texto diz e como faz para dizer o que diz (BARROS, 2005). Em seguida, propomos um caminho para a mediação da leitura do livro tendo por base a leitura realizada. Por fim, refletimos a respeito do que propusemos como atividades de mediação e sobre a 
mediação como fazer sensível e necessário para que a leitura e a produção de sentidos aconteçam. Este percurso pretende responder ao questionamento: como mediar a leitura do livro de imagem de literatura infantil?

\section{Ler o livro de imagem, construir efeitos de sentido por meio da linguagem visual}

A leitura que apresentamos a seguir assume a perspectiva teórica da semiótica discursiva. O percurso de produção de sentido decorrente dessa leitura é ponto de partida da experiência de mediação cuja organização didática será descrita na terceira parte deste texto.

Para a semiótica discursiva, a leitura é compreensão do modo como o sentido se dá, sendo que essa possibilidade é decorrente "da reunião [...] de dois planos que toda linguagem possui: o plano da expressão e o plano do conteúdo" (FLOCH, 2001, p. 9). No plano da expressão, temos os elementos sensíveis da linguagem visual (formas, cores, ocupação do espaço, materialidade). No plano do conteúdo, estabelecem-se os significados que decorrem da relação entre os elementos da expressão na constituição do texto visual que lemos.

A pressuposição recíproca entre esses dois planos - expressão e conteúdo - é o que estabelece a semiose, isto é, a possibilidade de a significação acontecer. Tal pressuposição pode ser compreendida a partir da total conformidade entre os planos, o que configura uma conformidade simbólica ou a semiose é estabelecida na textualidade entre as categorias de expressão e de conteúdo que a constituem o enunciado, configurando uma relação semissimbólica (FLOCH, 2001). No livro de imagem, a significação se constrói a partir de uma conformidade semissimbólica, de maneira que expressão e conteúdo são descritos e significados primeiramente a partir do texto que se mostra ao leitor e, posteriormente, podem estabelecer relações simbólicas com outros contextos. O sentido emerge primeiro do texto e da sua constituição para, depois, estabelecer relações contextuais e próximas dos leitores, pois, como afirma Barros (2005, p. 78): “O exame interno do texto não é suficiente [...] para determinar os valores que o discurso veicula. [...] é preciso inserir o texto no contexto de uma ou mais formações ideológicas que lhe atribuem, no fim das contas, o sentido."

Para explicitar essa relação produtora de sentido, traçamos o percurso gerativo de sentido $^{2}$ de um livro de imagem. O desenho desse percurso, a partir do qual a semiótica

\footnotetext{
${ }^{2}$ O percurso gerativo de sentido é o modo como a semiótica descreve a construção o sentido de um texto, em um movimento que parte da abstração até alcançar a concretude do sentido, demonstrando a complexificação dessa produção a partir da reciprocidade entre expressão e conteúdo (BARROS, 2005).
} 
discursiva compreende a produção de sentido, será também importante, como já dissemos, na organização da proposta didática de leitura mediada.

Esse percurso, que auxilia a traçar a geração do sentido, complexifica o sentido, aprofundamento nas camadas de significação do texto em um movimento que "[...] vai do mais simples ao mais complexo, do mais abstrato ao mais concreto"(GREIMAS; COURTÉS, 2008, p. 233). A geração do sentido conforme este modelo organiza-se em três níveis para que essa complexidade se estabeleça e permita acessar as possibilidades de significação do texto: nível fundamental, nível narrativo e nível discursivo (BARROS, 2005).

O nível fundamental é o que delimita uma oposição fundamental que estará presente ao longo do texto. O nível narrativo é descrito a partir das "transformações, advindas da maneira como esses opostos se relacionam no desenvolvimento das ações" (NUNES, 2013, p. 96). E, o último nível do percurso, o mais complexo, o nível discursivo, define as categorias de tempo, espaço e pessoa na produção do sentido.

No texto visual, esse percurso é construído por meio da desconstrução do texto, tendo como ponto de partida os elementos do plano de expressão. Assume-se a expressão visual como ponto de partida pois "a superfície pintada ou desenhada não revela, mediante nenhum artifício ostensivo, o processo semiótico que se pensa estar aí inscrito" (GREIMAS, 2004, p. 86)". A leitura da imagem acaba por ser a compreensão de como os elementos de expressão que a constituem se organizam, considerando que se trata de um texto que não é linear nem unidimensional como o texto escrito no mundo ocidental. Isso nos aproxima teoricamente da vertente da semiótica geral que se detém a compreender o sentido do texto visual: a semiótica plástica.

O ponto de partida dessa leitura, baseada na semiótica plástica, é o olhar que se volta para a imagem e, depois disso, passa a vê-la, desconstruindo-a, atento aos elementos de expressão e às suas possibilidades de sentido em relação a eles próprios e o enunciado discursivo que propõem. O que esse movimento, da semiótica plástica que parte dos elementos de expressão, possibilita é rejeitar "a confusão do visível e do falável; isso não significa, pelo contrário, que queremos fazer do visível um modo de existência do inefável (FLOCH, 1985, p. 14, tradução nossa ${ }^{3}$ ). O que olhamos é visto com olhos atentos e conscientes para o sentido que pode ser produzido, vê-se e se sente, de maneira sensível e inteligível e a partir do sentir que se torna possível descrever. Em outras palavras, não se trata

\footnotetext{
3 "La sémiotique plastique commence par refuser la confusion du visible et du dicible; cela ne signifie pas, bien au contraire, qu'on veuille faire du visible un mode d'existence de l'ineffable." (FLOCH, 1985, p. 14).
} 
apenas de listar o que se vê, em uma descrição mecânica e isolada de cada elemento sensível, mas de compreender como esses elementos se relacionam, estabelecendo possibilidades de sentido a partir das relações apreendidas.

Figura 1 - Capa do livro A menina e o tambor

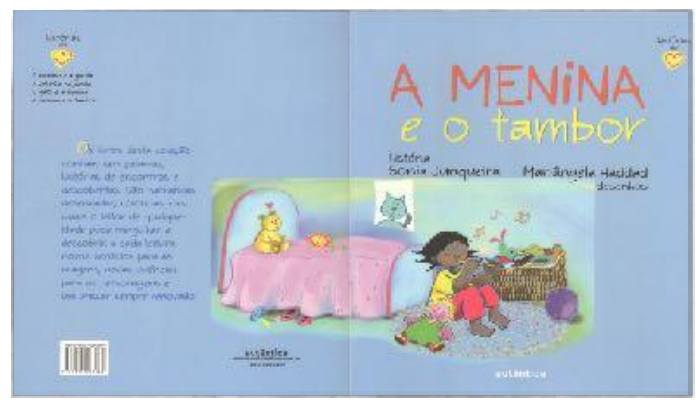

Fonte: Imagem digitalizada, arquivo pessoal

A menina e o tambor (JUNQUEIRA, 2009) $)^{4}$ (Figura 1) conta a história de uma alegre menina que se depara com pessoas tristes ao seu redor ${ }^{5}$. Ela tenta, então, de várias maneiras, transmitir alegria a essas pessoas. As tentativas, no entanto, são frustradas até o momento em que ela ouve a batida do seu coração e percebe a semelhança do som produzido por seu corpo com o de um tambor. A semelhança sonora entre as batidas do coração e de um instrumento de percussão é o elemento narrativo que provoca a virada da história, da tristeza à felicidade. As batidas do tambor, que é tocado pela menina depois de sua descoberta, contagiam o coração das pessoas, fazendo-as se sentirem felizes.

A história, narrada somente por imagens, tem como personagem principal uma menina cujas ações são voltadas para os demais personagens, que a instigam a buscar uma solução. Os espaços, onde essas ações acontecem, são o quarto da menina e as ruas por onde ela circula e convive com as outras pessoas. O tempo não é cronologicamente determinado; compreende o período do desenrolar dos fatos em que a menina percebe o problema - a tristeza e a preocupação que atingem as pessoas à sua volta - e a sua reflexão, que quase a conduz também à tristeza, mas que a faz alcançar a solução.

\footnotetext{
${ }^{4} \mathrm{O}$ livro A menina e o tambor apresenta uma narrativa-visual que tem na sua autoria uma particularidade, pois a história foi concebida por Sônia Junqueira, e as imagens que constituem o texto foram produzidas por Mariangela Haddad, conforme consta na capa do livro. A ficha catalográfica da obra, porém, indica apenas Sônia Junqueira na autoria, por isso a referência conforme a ABNT faz menção apenas a ela.

${ }^{5}$ A leitura semiótica apresentada a partir daqui foi realizada como parte da pesquisa Leitura mediada do livro de imagem no Ensino Fundamental: letramento visual, interação e sentido (NUNES, 2013).
} 
Os elementos narrativos sucintamente apresentados fazem parte do plano de conteúdo onde identificamos efeitos de sentido que se deflagram, inicialmente, pela oposição de ideias que se sobrepõem ao longo da história, de modo que uma recebe uma qualificação eufórica e um valor positivo, e a outra é qualificada como disfórica e com valor negativo. Na narrativa em questão, a ideia eufórica e positiva é a alegria, enquanto a tristeza assume papel disfórico e negativo. Essa valorização é estabelecida considerando o texto e a construção narrativa que analisamos. Os valores positivos e negativos não se configuram como simbólicos. A alegria é positiva, pois é ela que a personagem persegue em oposição à tristeza que ela busca superar no transcorrer dos fatos e pelo modo como os elementos de expressão se relacionam com o conteúdo enunciado.

A alegria da menina, actante central da narrativa, se confronta diretamente com a tristeza das pessoas pelas quais ela passa ou vê nas ruas. A oposição /alegria/ versus /tristeza/ ou /vivacidade/ versus /apatia/ revelam a base semântica dessa história. É em torno dessas ideias que a narrativa é construída. A alegre menina se apresenta caminhando e assobiando tranquilamente e percebe a tristeza das pessoas (FIGURA 2).

Figura 2 - Cena de abertura da narrativa

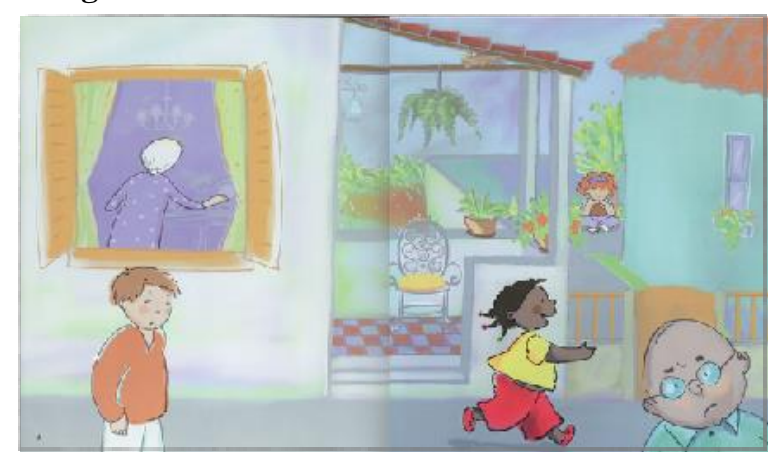

Fonte: Imagem digitalizada, arquivo pessoal

A reversão da tristeza/apatia em estado de alegria/vivacidade decorre primeiro do modo de ser da menina no início da história - conforme demonstra a sua primeira imagem: alegre, caminhando e assobiando tranquilamente - e, depois, por perceber a tristeza das pessoas pelas quais cruza nas ruas. Essa sua percepção a leva a tentar fazer graça, usando um nariz de palhaço, mencionar algo sobre o sol, oferecer flores para os adultos e doces para as crianças, dentre outras ações, para tentar mudar o comportamento das pessoas. No entanto, nada parece funcionar, a tristeza continua prevalecendo e, inclusive, quase contagia a menina. 
A mudança surge, no entanto, quando a menina ouve seu coração e tem uma ideia. A imagem mostra em sequência a menina baixando a cabeça e corporalmente ficando retraída. A figura do coração na cor vermelha contrasta com sua camiseta amarela, e signos verbais "tum, tum, tum" indicam a sonoridade das batidas. Para indicar que ela teve uma ideia, o foco se concentra em seu rosto, que aparece em aproximado, sorrindo, enquanto uma imagem mostra um balão como se ela repetisse para si o som das batidas do coração. Em seguida, outro balão com pontos de exclamação indica sua euforia. A sonoridade figurativizada ${ }^{6}$ pelos signos verbais "tum, tum, tum" acompanha toda a sequência de imagens. A menina corre, então, para casa em busca de seu tambor. A ação seguinte será sair às ruas e tentar contagiar as pessoas com o som da batida do tambor, uma batida como a do coração, um som que poderá fazer as pessoas lembrarem que estão vivas, e isso é motivo de alegria.

A menina com seu estado de alegria, em oposição às pessoas tristes, mas que são contagiadas pelo som do instrumento, e a batida do tambor auxiliam a compor figurativamente a temática discursiva: o fato de que a alegria é algo que pode estar dentro de nós, algo que pode se revelar pelo simples fato de estarmos vivos, com nosso coração batendo em pleno funcionamento.

É a partir dessa figurativização que temos acesso aos elementos sensíveis do plano de expressão. O modo com que essas figuras são apresentadas ao longo das páginas, a organização topológica da narrativa, nos permite ter uma visão privilegiada de toda a história. Somos testemunhas dos fatos e, por isso, com nosso olhar participativo, conferimos veracidade ao que está sendo contado. Nós, os leitores, somos espectadores e também cúmplices da menina que nos olha, procurando apoio em seu momento de quase tristeza e também quando consegue encontrar uma solução para alterar o humor das pessoas à sua volta.

Acompanhamos, na dupla de páginas, uma sequência de cenas que nos mostram as ações da menina. Temos acesso a detalhes relevantes do que se passa ou uma visão panorâmica da cena, podendo acompanhar a reação de todos os que dela participam. Observamos a tudo e a todos e somos observadores parceiros da menina que, como já vimos, busca apoio no nosso olhar leitor, que funciona também como ancoragem na realidade, tornando verossímil aquilo que é narrado.

\footnotetext{
${ }^{6}$ Valendo-nos de alguns verbetes do Dicionário de semiótica (GREIMAS; COURTÉS, 2008), podemos realizar a seguinte inferência a respeito do conceito de figurativização: para a semiótica discursiva a figurativização é um subcomponente da semântica, é o que possibilita que um elemento sintático seja reconhecido como figura (com correspondente na semiótica do mundo natural), tendo valor semântico e sintático correspondente à construção enunciativa da qual faz parte.
} 
Esse mesmo olhar privilegiado é capaz de perceber a alternância de formas na apresentação dos sujeitos da ação na sua transformação da tristeza apática em alegria vivaz, com feições e posturas corporais que se alternam de um estado a outro. Percebemos, em uma rápida comparação de duas duplas de páginas que mostram cenas semelhantes, a mudança no modo com que olhos e bocas das pessoas são apresentados, bem como de uma postura corporal mais ereta para uma mais descontraída. Linhas retas e formas pequenas revelam a tristeza nos rostos; enquanto linhas curvas, ascendentes e formas grandes, com bocas escancaradas em amplos sorrisos e corpos dançantes traduzem a alegria na cena seguinte. $\mathrm{O}$ reforço dessa oposição - de uma tristeza marcante que depois, graças à ação da menina, é transformada em alegria -, é marcado também no modo com que a cor é utilizada.

A cor é como afirma o ilustrador Rui de Oliveira, "um dos elementos constitutivos da imagem narrativa que possui o maior poder emotivo e evocativo" (OLIVEIRA, 2008, p. 50). Nas imagens da história aqui analisadas, percebemos um contraste entre cores vivas, para destacar a alegre personagem, e tons pastéis dessas mesmas cores na apresentação das pessoas tristes que estão próximas a ela. Essa diferenciação, no desenrolar da narrativa, evidencia o estado inicial das pessoas tristes e preocupadas, que influenciam até mesmo o ambiente que ocupam, tudo representado por cores mais claras - em contraste com a menina que, desde o início, surge com cores intensas (o vermelho e o amarelo das roupas que veste para exemplificar), ressaltando sua alegria.

A constituição plástica dessa obra, portanto, não pode ser ignorada no processo de produção de sentido. O entrelaçamento de formas e cores e o modo com que o espaço da página é tomado, auxiliam na identificação de possíveis efeitos de sentido que reforçam o conteúdo discursivo dessa narrativa. Essa compreensão sobre a produção de sentido a partir da constituição do texto torna-se caminho para pensar como mediar a leitura desse livro, auxiliando a criança a ler com sensibilidade, valendo-se da análise, da comparação, da inferência.

\section{Proposta de organização didática para a leitura mediada de A menina e o tambor (livro de imagem)}

A compreensão, de acordo com a teoria semiótica discursiva, de que essas imagens são textos constituídos por um plano de expressão e um plano de conteúdo da teoria é o caminho que nos permite entender como se dá a interação entre a constituição discursiva da narrativa e a plasticidade da imagem. Isso foi o que descrevemos e apresentamos na análise anterior, 
respondendo à pergunta como o texto produz sentido. A pergunta nesta parte final do texto é propor uma experiência didática que auxilie o leitor a realizar esse percurso de construção do sentido lendo/vendo e compreendendo como os elementos plásticos são utilizados na estrutura narrativa.

As ações que descrevemos têm por base os quatro princípios citados no início deste texto e assumem a perspectiva teórica também como modo de organização metodológica da proposta didática. A leitura será mediada seguindo o percurso gerativo de sentido, percorrendo o mesmo caminho feito na leitura analítica de A menina e o tambor (JUNQUEIRA, 2009), em um movimento que busca aprofundar o olhar para o texto, de um nível mais abstrato até a concretude dos sentidos estabelecidos. Para isso, dividimos as ações de mediação em quatro momentos distintos.

O primeiro deles se propõe a explorar as imagens e mapear elementos da narrativa, um momento essencial em qualquer experiência que pretenda a construção do conhecimento. Esse encontro inicial com o texto a ser lido é o momento de provocar a emoção do leitor, uma emoção que pretende complexificar e diversificar o seu modo de ser e agir frente a esse texto. A aproximação inicial do texto é o momento de ultrapassar o mero ver as imagens e alcançar o olhar com sentido. Como argumenta Vigotski (2004, p. 135): “Um comportamento emocionalmente colorido adquire um caráter inteiramente diverso do comportamento insípido". As ações iniciais, portanto, motivam para buscar a curiosidade e também os conhecimentos prévios dos leitores já acostumados a interagir com o texto narrativo, sejam eles orais ou escritos.

Após motivar e reavivar conhecimentos prévios, a mediação volta-se a investigar o texto em busca de ideias opostas que podem ser a base do que é narrado. Inicia-se o percurso gerativo de sentido de maneira mais sistematizada. Em seguida, tendo-se inferido essas ideias opostas, o olhar volta-se para o texto novamente para buscar elementos de expressão que deixam marcas da presença ou ausência dessas ideias ao longo do texto, observando se há prevalência de uma, se elas se alternam, qual se sobressaia, em que momentos cada uma delas está presente ou ausente. Por fim, os questionamentos virão para que os leitores construam possibilidades de sentido para o que foi lido; uma construção final que busca ser construída a partir de todo o percurso de leitura em que a narrativa foi lida diferentes vezes, com olhares diferentes para um mesmo texto.

A partir dessa descrição que procurou sistematizar as etapas da experiência de leitura mediada, apresentamos, a seguir, um quadro com algumas sugestões de ações para mediar a 
leitura em cada um dos momentos estabelecidos para auxiliar na produção de sentidos e compreensão.

QUADRO 1 - Ações para mediar para a leitura mediada de A menina e o tambor (JUNQUEIRA, 2009)

1- MOTIVAÇÃO - iniciar a leitura e preparar para o percurso gerativo de sentido.

- Apresentar o livro, uma leitura que pode ser coletiva, com a professora apresentando o livro à turma em pequenos grupos ou individual (dependendo da quantidade exemplares disponíveis).

- Construir um mapa da narrativa identificando os elementos essenciais: personagem principal, personagens secundários, tempo, espaço, principais fatos, problema, clímax, solução do problema.

- Propor, a partir de uma lista de ideias opostas, a combinação entre elas (formar pares de opostos), incluindo nessa lista algumas ideias que podem ser relacionadas com a narrativa, tendo como fonte a leitura do mediador. Por exemplo: sol x chuva, criança x adulto, animação x desanimação, silêncio x barulho, alegria $\mathrm{x}$ tristeza, cheio $\mathrm{x}$ vazio, dentro $\mathrm{x}$ fora.

Observação: A MOTIVAÇÃ̃ prepara para as ações didáticas que acontecerão nos momentos seguintes da mediação: inferências iniciais sobre os elementos de expressão visual que constroem o texto e a narrativa apresentada, sobre possíveis oposições de ideias que se alternam ao longo da narrativa

\section{2- LER/VER DE NOVO para encontrar oposições fundamentais para os sentidos do texto}

- Voltar ao texto com a lista de ideias opostas construída na MOTIVAÇÃO e analisar qual(is) está/estão presentes, que outras podem ser inseridas na lista, qual(is) é/são mais presentes ao longo do desenrolar da narrativa.

- Escolher ou indicar uma dupla de ideias e apontar elementos do texto que demonstrem serem elas a mais relevante no seu ponto de vista de leitura.

\section{3- LER/VER DE NOVO para ampliar o olhar em relação aos elementos da narrativa}

- Voltar ao texto com o mapa da narrativa construído na MOTIVAÇÃO e complementá-lo, relacionando os elementos com as suas características sensíveis (cores, formas, espaço/perspectiva) que constituem as imagens.

4- LER/VER DE NOVO as imagens do livro em associação com outras imagens, assumindo a narrativa e percebendo os diferentes modos de enunciá-la

- Ler outros textos (fotografias, pinturas, esculturas) que enunciem discursos similares aos construídos a partir da leitura e da mediação das ações didáticas anteriores.

- Agregar as leituras: a) ao esquema das ideias opostas e seus modos de apresentação no desenrolar dos fatos; b) ao mapa da narrativa e às características sensíveis da linguagem visual empregadas para apresentá-las.

- Estabelecer aproximações e diferenciações dos modos de enunciar a partir dos outros recursos expressivos utilizados pelas imagens, ampliando modos de ver o mundo e produzir sentidos.

Fonte: Elaborado pela autora.

Esse conjunto de ações se propõe a auxiliar o leitor a encontrar o texto com diferentes modos de vê-lo, com atenção voltada a aspectos diferentes, mas que se complementam na construção de possíveis sentidos para o que lê. Cada um dos momentos possibilita associar o conteúdo à expressão, compreendendo as relações de reciprocidade estabelecidas no texto lido. 
A realização dessas ações traz implicada a relevância de que o mediador seja um leitor experiente diante do texto visual para que possa, ao longo desse caminho, propor questionamentos mediadores coerentes e potentes para a produção de sentido. Esse pressuposto é construído considerando o conceito de "andaime" (scaffolding, do inglês) e que deriva da perspectiva sociocultural de desenvolvimento da aprendizagem descrita por Vigotski (1998). Esse conceito pode ser compreendido, segundo Bortoni-Ricardo et al (2017, p. 27), conforme duas noções deduzidas de estudos sociolinguísticos.

$\mathrm{Na}$ primeira, a linguagem e, consequentemente, a interação entre pessoas são consideradas fundamentais no processo de aprendizagem; na segunda, as ações humanas, incluindo-se aí a linguagem, constituem esforços construídos de forma cooperativa e conjunta pelos interagentes.

A experiência como leitor, em uma atitude leitora cooperativa, precisa também estar associada ao planejamento de todo esse percurso, o que implica um saber-fazer relacionado à docência. Organizar um planejamento para a mediação de leitura, porém, não significa ter em mãos uma proposta fechada, mas sim uma organização que oferece possíveis direções, uma trajetória que pode ser modificada, considerando que essa flexibilidade do planejamento, no entanto, não minimiza sua importância, pois os improvisos e as mudanças tendem a ser mais articulados às necessidades das crianças quando o profissional pensou antes sobre o que iria fazer e o motivo pelo qual iria fazer o que estava planejando (LIMA et al, 2012).

Assim, o objetivo, o porquê de pensar o caminho, é estabelecido, mas o modo como se chegará até ele, apesar de poder ser previsto (uma previsão necessária para que o objetivo não se perca), não é limitado a um único modo de acontecer.

Todo o percurso mediador para a produção de sentido também não ignora que a leitura da imagem, assim como a leitura de outros textos, implica uma atitude leitora que decorre não somente de questões cognitivas, mas também de relações de afetividade. De maneira ampla, as situações vividas em sala de aula dependem de diferentes fatores (autoconceito, expectativas de sucesso, expectativas de prazer ou de utilidade, pressões sociais e culturais) e de como os sujeitos envolvidos demonstram isso. A atenção a esses fatores por parte do professor, mediador por excelência do espaço da sala de aula, segundo Cramer e Castle (2001, p. 30), precisa existir, pois será "a melhor esperança de sucesso" do que acontece em sala de aula.

A mediação da leitura começa por contagiar para ler: "optar por ler é mais importante do que gostar de ler, e a escolha é muito circunstancial” (CRAMER E CASTLE, 2001, p. 26). 
Diante do texto-imagem, essa opção talvez não seja tão natural, principalmente se considerarmos que a imagem nem sempre recebe a mesma atenção na prática pedagógica na escola, provavelmente em decorrência de um entendimento restrito de que a visão como sentido é sinônimo de ler. Por isso, o percurso de mediação da leitura de imagem que propomos não é apenas restrito ao desenvolvimento de uma prática do ler imagem, mas é também uma prática de sensibilidade ou educação do olhar ou de letramento visual, envolvendo leitores, crianças dos Anos Iniciais do Ensino Fundamental, em uma experiência sensível e inteligível de produção de sentido.

\section{Considerações finais: mediar a leitura do livro de imagem, um fazer que exige um mediador}

O fazer mediador diante do livro de imagem é o que possibilitará que todas essas ações propostas sejam planejadas, porém esse fazer não prescinde do outro, de quem é mediado. Os sentidos produzidos ao ler e por que seu leu decorrem das interações entre texto e leitor, entre leitores - na sala de aula, a leitura é muito mais solidária do que solitária, como podemos concluir com base nas ideias de Jorge Larrosa (BONDÍA, 2003) e Rildo Cosson (COSSON, 2006) -, entre mediador e leitores - não ignorando que o mediador também é leitor. No entanto, o mediador torna-se figura imprescindível pela sua intencionalidade, pela sua crença de que o leitor pode ser mediado (NUNES, 2007), e essas crenças o auxiliam a exercer o seu papel, promovendo uma interação em que modos de ser e agir são essenciais para que os sentidos sejam produzidos.

Esses modos de ser e agir do mediador podem reduzir ou ampliar as possibilidades de sentido em uma interação. Essa concepção, que associa interação e sentido, é construída pela “semiótica das situações" (LANDOWSKI, 2005, p. 11) ou pela denominada sociossemiótica (LANDOWSKI, 2014b). Essa perspectiva assumida pela semiótica, a partir da obra Da imperfeição (2002), do criador da semiótica discursiva, o lituano Algirdas Julien Greimas, e continuada por Eric Landowski, descrita no livro Interações arriscadas (2014a), "não ignora o rigor da ciência do texto de seus primórdios, mas [...] procura de modo mais filosófico voltar-se a compreender de que modo o mundo nos provoca, se disforicamente ou euforicamente, carregado de sentido" (NUNES, 2013, p. 100).

Para a semiótica do vivido, a disforia ou euforia, ou o olhar para o mundo e suas experiências com maior ou menor sensibilidade, é decorrente do modo com que interagimos com o mundo e com o outro. Para Landowski (2014a, p. 16), nossa presença e relação com o 
mundo e com o outro acontece a partir de variados regimes de interação. $\mathrm{O}$ autor recupera dois regimes de sentido descritos por Greimas (2002) e conceitua outros dois, estabelecendo um conjunto de quatro regimes de interação (LANDOWSKI, 2014a): "a interação programada, fundada no princípio da regularidade, a interação manipulada, fundada no princípio da intencionalidade, a interação ajustada, fundada no princípio da sensibilidade e, a interação acidental, fundada no princípio da aleatoriedade" (NUNES, 2016, p. 2995).

Espera-se que o fazer do mediador - que parte de um planejamento, organiza suas estratégias de intervenção didática, compreende que seu leitor mediado é parte do processo e também produtor de sentidos a partir da leitura -, oscile entre esses modos de interagir na experiência de leitura mediada. Essa oscilação entre regimes de interação constitui um caminho, inicialmente, reduzido aos sentidos de sua própria leitura decorrentes do planejamento da organização didática (uma interação programada), mas que ser colocado em prática na interação com os leitores em sala de aula, entende a necessidade de relativizar o programa e assumir um fazer estratégico que pretende seduzir os leitores o desenrolar da leitura planejada. Portanto, essa sedução não ignora que a mediação acontece com leitores, sujeitos também capazes de produzir sentidos diversos daqueles que o mediador construiu. Assim, a interação mediada busca a sensibilidade do outro (uma interação por ajustamento), ouvindo e dando abertura aos sentidos de todos os envolvidos.

Mediar, portanto, é uma interação que oscila entre a rigidez, a estratégia para motivar e a sensibilidade que deixa o outro participar livremente (NUNES, 2013; 2016). Esse fazer é essencial para que o leitor em formação tenha possibilidade de interagir de modo sensível com a imagem como tex to produtor de sentido.

\section{Referências}

ACASO, María. La diferencia entre ver y leer. In: Esto no son las torres gemelas: como aprender a leer la televísion y otras imágenes. Madrid: Catarata, 2006, p. 89-91.

BARROS, Diana Luz Pessoa de. Teoria semiótica do texto. São Paulo, Ática, 2005.

BONDÍA, Jorge Larrosa. La defensa de la soledad. In: La experiencia de la lectura: estudios sobre literatura y formación. México: FCE, 2003, 597-605.

BORTONI-RICARDO, Stella Maris et al. Formação do professor como agente letrador. São Paulo: Contexto, 2017.

COSSON, Rildo. Letramento literário: teoria e prática. São Paulo: Contexto, 2006. 
CRAMER, Eugene H.; CASTLE, Marrietta (Orgs.). Incentivando o amor pela leitura. Tradução de Maria Cristina Monteiro. Porto Alegre: Artmed, 2001.

FLOCH, Jean Marie. Introduccion: pour une sémiotique plastique. In: .Petites mythologies de l'oiel et de l'esprit: pour une sémiotique plastique. Paris-Amsterdam: Éditions Hadès-Benjamins, 1985, p. 11-19.

FLOCH, Jean Marie. Alguns conceitos fundamentais em semiótica geral. Documentos de Estudo do Centro de Pesquisas Sociossemióticas. São Paulo: Centro de Pesquisas Sociossemióticas, São Paulo, 2001.

GREIMAS, Algirdas Julien. Da imperfeição. Tradução de Ana Claudia de Oliveira. São Paulo: Hacker Editores, 2002.

GREIMAS, Algirdas Julien; COURTÉS, J. Dicionário de semiótica. São Paulo: Contexto, 2008.

HERNÁNDEZ, Fernando. De qué hablamos cuando hablamos de Cultura Visual?. Educação \& Realidade, Porto Alegre, v. 30, n.2 (jul/dez 2005) p. 9-34.

JUNQUEIRA, Sonia. A menina e o tambor. Desenhos de Mariângela Haddad. Belo Horizonte, Autêntica Editora, 2009.

LANDOWSKI, Eric. Aquém ou além das estratégias, a presença contagiosa. Documentos de estudo do Centro de Pesquisas Sociossemióticas: 3. São Paulo: CPS, 2005.

LANDOWSKI, Eric. Interações arriscadas. Trad. Luiza Helena Oliveira da Silva. São Paulo: Estação das Letras e Cores: Centro de Pesquisas Sociossemióticas, 2014a.

LANDOWSKI, Eric. Sociossemiótica: uma teoria geral do sentido. Galaxia. São Paulo, Online, n. 27, p. 10-20, jun. 2014b.

LIMA, Juliana de Melo; TELES, Rosinalda; LEAL, Telma Ferraz. Planejar para integrar saberes e experiências. In: Brasil. Secretaria de Educação Básica. Diretoria de Apoio à Gestão Educacional. Pacto nacional pela alfabetização na idade certa: planejando a alfabetização e dialogando com diferentes áreas do conhecimento: ano 02, unidade 06. Ministério da Educação, Secretaria de Educação Básica, Diretoria de Apoio à Gestão Educacional. Brasília: MEC, SEB, 2012, p. 06-13.

NUNES, Marília Forgearini. A leitura de narrativas infantis verbo-visuais: interação do leitor com a palavra e a visualidade por meio da mediação. Santa Cruz do Sul: UNISC, 2007, 281f. Dissertação, Programa de Pós-graduação em letras, Faculdade de Letras, Universidade de Santa Cruz do Sul, Santa Cruz do Sul, 2007.

NUNES, Marília Forgearini. Leitura mediada do livro de imagem no ensino fundamental: letramento visual, interação e sentido. Porto Alegre, SP: Tese (Doutorado). Universidade Federal do Rio Grande do Sul, Faculdade de Educação, Programa de Pós Graduação em Educação, Porto Alegre, BR-RS, 2013. 
NUNES, Marília Forgearini. Leitura do livro de imagem no contexto escolar: algumas reflexões necessárias. In: GABRIEL, Rosângela et al (Orgs.). Tecendo conexões entre cognição, linguagem e leitura. Curitiba: Multideia, 2014, p. 177-187.

NUNES, Marília Forgearini. Mediação em práticas de letramento visual: programação, manipulação e ajustamento. In: Encontro Nacional de Pesquisadores em Artes Plástica, 25, 2016, Porto Alegre. Anais da 250 Encontro da ANPAP, Porto Alegre: ANPAP, 2016, p. 2992-3001. Disponível em: http://anpap.org.br/anais/2016/simposios/s6/marilia_forgearini_nunes.pdf . Acesso em: 29 Set. 2020.

OLIVEIRA, Ana Claudia de. Repetição e diferença: uma dupla face. Farol, Vitória, 1999, n. 1, p.107-125.

OLIVEIRA, Rui de. Pelos Jardins Boboli: reflexões sobre a arte de ilustrar livros para crianças e jovens. Rio de Janeiro: Nova Fronteira, 2008b.

PANOZZO, Neiva. Literatura infantil: uma abordagem das qualidades sensíveis e inteligíveis da leitura imagética na escola. 2001. 169 f. Dissertação (Mestrado) - Faculdade de Educação, Universidade Federal do Rio Grande do Sul, Porto Alegre, 2001.

PANNOZO, Neiva. Leitura no entrelaçamento de linguagens: literatura infantil, processo educativo e mediação. 2007. 211 f. Tese (Doutorado em Educação) - Faculdade de Educação, Universidade Federal do Rio Grande do Sul, Porto Alegre, 2007.

PARSONS, Michael J. Compreender a arte: uma abordagem à experiência estética do ponto de vista do desenvolvimento cognitivo. Lisboa: Presença, 1992.

PILLAR, Analice Dutra. Leitura da imagem. In: PILLAR, Analice Dutra et al. Pesquisa em artes plásticas. Porto Alegre: UFRGS/ANPAP, 1993. p. 77-86.

PILLAR, Analice Dutra. Leitura e releitura. In: . A educação do olhar no ensino das artes. Porto Alegre: Mediação, 2003, p. 9-21.

RAMALHO E OLIVEIRA, Sandra. Imagem também se lê. São Paulo: Edições Rosari, 2009.

REBOUÇAS, Moema. O discurso modernista da pintura (Tarsila, Segall, De Fiori, Guignard e Volpi). 2000. Tese (Doutorado) - Pontifícia Universidade Católica de São Paulo, São Paulo, 2000.

ROSSI, Maria Helena Wagner. Imagens que falam: leitura da imagem na escola. 3. ed. Porto Alegre: Mediação, 2003.

VIGOTSKI, Lev. Semenovich. A formação social da mente: o desenvolvimento dos processos psicológicos superiores. Tradução de José Cipolla Neto, Luís Silveira Menna Barreto, Solange Castro Afeche. 6.ed. São Paulo: Martins Fontes, 1998. 
VIGOTSKI, L.S. A educação no comportamento emocional. In: Psicologia

pedagógica. Tradução de Paulo Bezerra. 2. ed. São Paulo: Martins Fontes, 2004, p. 127-147.

Recebido em: 03/05/2020

Aceito para publicação em: 25/08/2020 